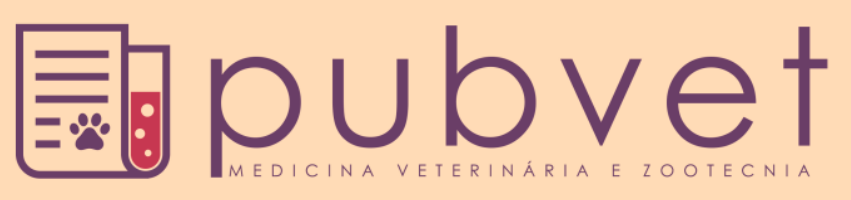

HTTP://DX.DOI.ORG/10.22256/PUBVET.V11N11.1138-1150

\title{
Aminoácidos de cadeia ramificada na alimentação de suínos: Revisão
}

\author{
Laura Marcela Diaz Huepa ${ }^{1 *}$, Joyce Sato ${ }^{1}$, Juliana Beatriz Toledo ${ }^{2}$, Alessandra Nardina \\ Tricia Rigo Monteiro ${ }^{3}$, Paulo Cesar Pozza ${ }^{2}$
}

${ }^{1}$ Doutora em Zootecnia. Universidade estadual de Maringá. Maringá, PR-Brasil. E-mail: lauramvz28@hotmail.com*; joycesato1986@yahoo.com.br

${ }^{2}$ Professor(a) Universidade Estadual de Maringá. Departamento de Zootecnia. Maringá, PR-Brasil. E-mail: juliana.b.toledo@gmail.com; pcpozza@uem.br

${ }^{3}$ INRA Agrocampus Ouest, UMR1348 Pegase, 35590, Saint-Gilles, France. E-mail: a_monteiro@zootecnista.com.br

*Autor para correspondência

RESUMO. A proteína é o componente que mais interfere no crescimento animal, influenciando parâmetros como o ganho de peso, o consumo diário de ração e a conversão alimentar. Este componente orgânico esta constituído por unidades polimerizadas de aminoácidos, que são classificados em aminoácidos essenciais e não essenciais. Os aminoácidos de cadeia ramificada (leucina, valina e isoleucina) fazem parte do grupo dos aminoácidos essenciais caracterizados por sua estrutura de cadeias laterais ramificadas, são oxidados como combustível principalmente pelos tecidos muscular, adiposo, renal e encefálico, tendo a capacidade de influenciar diretamente a síntese de proteína, além de possuir um efeito sinérgico com a insulina para estimular a captação de glicose pelas células. Estas características interessam aos nutricionistas que tem como objetivo otimizar dietas para suínos que permitam atender os requerimentos nutricionais dos animais, melhorando os parâmetros produtivos e evitando excessos de ingredientes nas dietas para diminuir a poluição ambiental. O objetivo desta revisão é facilitar o conhecimento e importância dos aminoácidos de cadeia ramificada na nutrição de suínos.

Palavras chave: Leucina, isoleucina, valina, suínos, nutrição

\section{Branched chain amino acids in feeding of pigs: Review}

ABSTRACT. Protein is the component that most interferes with animal growth, influencing parameters such as weight gain, daily feed intake and feed conversion ratio. This organic component consists of polymerized units of amino acids, which are classified as essential and non-essential amino acids. The branched-chain amino acids (leucine, valine and isoleucine) are part of the group of essential amino acids characterized by their branched chain structure, they are oxidized as fuel mainly by the muscular, adipose, renal and encephalic tissues, having the ability to directly influence the synthesis of protein, in addition to having a synergistic effect with insulin to stimulate the uptake of glucose by the cells. These characteristics are of interest to nutritionists who aim to optimize diets for pigs that meet the nutritional requirements of animals, improving production parameters and avoiding excess ingredients in diets to reduce environmental pollution. The objective of this review is to facilitate the knowledge and importance of branched chain amino acids in nutrition pigs.

Key words: Leucine, isoleucine, valine, swine, nutrition 


\section{Aminoácidos de cadena ramificada en la alimentación de cerdos: Revisión}

RESUMEN. La proteína es el compuesto que más interfiere en el crecimiento animal, influenciando parámetros como la ganancia de peso, el consumo de pienso y la conversión alimentar. Este compuesto orgánico se constituye por unidades polimerizadas de aminoácidos, que son clasificados en aminoácidos esenciales y no esenciales. Los aminoácidos de cadena ramificada hacen parte del grupo de los aminoácidos esenciales caracterizados por su estructura de cadenas laterales ramificadas, son oxidados como combustible principalmente por los tejidos muscular, adiposo, renal y encefálico, teniendo la capacidad de influenciar directamente la síntesis de proteína, además de poseer un efecto sinérgico con la insulina para estimular la captación de glucosa por las células. Estas características interesan a los nutricionistas que tienen como objetivo optimizar dietas para cerdos que permitan atender los requerimientos nutricionales de los animales, mejorando los parámetros productivos evitando excesos de ingredientes en las dietas para disminuir la contaminación ambiental. El objetivo de esta revisión es facilitar el conocimiento e importancia de los aminoácidos de cadena ramificada en la nutrición de cerdos.

Palabras clave: Leucina, isoleucina, valina, porcinos, nutrición

\section{Introdução}

O conhecimento das exigências nutricionais é fundamental para oferecer aos animais as quantidades adequadas de nutrientes para seu ótimo desenvolvimento e produtividade. As pesquisas realizadas nesta área permitem garantir um melhor desenvolvimento da espécie animal estudada; assim, a oferta de nutrientes deve ser planejada com o objetivo de otimizar o desempenho reprodutivo e produtivo, mantendo uma adequada condição corporal dos animais para garantir um produto de qualidade para o consumo humano.

Para alcançar estes objetivos, são necessários ajustes precisos nos requerimentos nutricionais dos animais e na estratégia de alimentação, principalmente se $\mathrm{o}$ foco de estudo for a exigência de aminoácidos (AA). Pesquisas demonstraram a importância da concentração de proteína bruta $(\mathrm{PB})$ e dos AA industriais, indispensáveis para uma formulação mais precisa, com base no conceito da proteína ideal (Richardson et al., 1965, Oestemer et al., 1973, Gomez et al., 2002, Zangeronimo et al., 2006, Lordelo et al., 2008, Gloaguen et al., 2014). Assim, a eficiência no aproveitamento dos ingredientes proteicos pelos não ruminantes depende da quantidade, da composição e da digestibilidade dos AA, de modo que as especificidades do aporte desses nutrientes sejam supridas. Os AA têm grande importância fisiológica, servindo como blocos de construção para proteínas e substratos para a síntese de substâncias de baixo peso molecular. Animais em crescimento (como suínos e aves) precisam de AA para formação do tecido muscular (proteína corporal). Assim, além da construção de blocos de proteínas, os AA também são necessários para diversas funções corporais, como $\mathrm{o}$ desenvolvimento de órgãos e ótimo funcionamento do sistema imunológico (Lehninger, 2006). Além disso, o conteúdo de proteína e AA devem ser considerados na formulação de rações para melhorar a eficiência de utilização dos nutrientes, o crescimento e o desenvolvimento, a reprodução, a lactação e o bem-estar dos animais ( $\mathrm{Wu}, 2014)$.

Os aminoácidos de cadeia ramificada (ACR), valina, isoleucina e leucina (Figura 1), fazem parte do grupo de AA essenciais necessários para mantença e crescimento tecidual. Os ACR caracterizam-se por sua estrutura de cadeias laterais ramificadas, sendo oxidados como combustível principalmente pelos tecidos muscular, adiposo, renal e encefálico (Lehninger, 2006). Além disso, por serem AA semelhantes em estrutura, compartilham as mesmas enzimas para suas reações de transaminação e descarboxilação oxidativa (Harper, 1984).

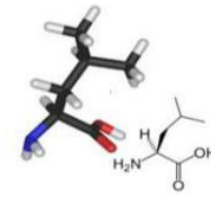

Leucina

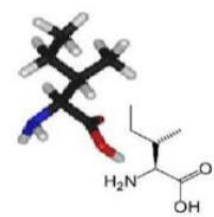

Isoleucina

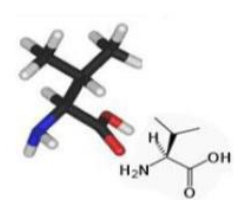

Valina
Figura 1. Estrutura dos aminoácidos de cadeia ramificada (ACR) (Adaptado de Lehninger (2006). 
A primeira etapa de metabolização dos ACR ocorre no músculo esquelético (transaminação reversível), sendo comum para a leucina, valina e isoleucina. $\mathrm{O} \alpha$-cetoácido formado pode ser utilizado para a ressíntese dos ACR no fígado, ou passar por uma descarboxilação oxidativa irreversível, levando à formação de derivados da CoA (Lehninger, 2006). Como os ACR compartilham as primeiras reações do seu metabolismo, vários trabalhos demonstraram que quantidades excessivas de leucina na dieta reduzem a disponibilidade de valina e isoleucina (Oestemer et al., 1973, Harper, 1984, Shimomura and Harris, 2006).

Apesar deste efeito da leucina sobre as concentrações de valina e isoleucina, estudos demostraram que a administração de leucina pode estimular a síntese proteica de leitões por meio da ativação da sinalização dos componentes que conduzem à tradução do mRNA (RNA mensageiro; Escobar et al. (2005), ou seja, os $\mathrm{ACR}$, principalmente a leucina, têm a capacidade de iniciar as vias de tradução de sinal do mRNA em proteína, estimulando também a síntese de proteínas por meio da associação do complexo ativo eIF4E (fator de transdução eucariótico). Os efeitos estimuladores de leucina na iniciação da tradução são mediados, em parte, através do alvo da proteína quinase da rapamicina em mamíferos (mTOR), onde tanto a sinalização da insulina e leucina convergem para promover uma resposta máxima à deposição muscular (Anthony et al., 2001). O mecanismo pelo qual a leucina e insulina promovem a síntese e inibem a degradação proteica está relacionado ao fato do que o aminoácido aumenta sua concentração intracelular (Mata and Navarro, 2009) e aquele hormônio polipeptídico é estimulado pelo consumo de alimento, causando uma diminuição na degradação de proteínas, maior captação de AA pela célula e aumento da síntese proteica. Este fenômeno se caracteriza como o "paradoxo da leucina", pois este AA apresenta importante estímulo sobre a síntese proteica, devido a seu efeito sobre a tradução do mRNA (Lehninger, 2006), ao passo que seu excesso, em dietas restritas em proteína, pode comprometer o aproveitamento dos outros ACR (Harper, 1984).

Os avanços obtidos nos últimos anos na área de nutrição animal proporcionaram a melhora no desempenho dos animais e a redução da contaminação ambiental, devido à formulação de rações baseadas no conceito de proteína ideal, a suplementação de AA industriais e a baixa porcentagem de $\mathrm{PB}$ nas dietas, diminuindo a excreção de nitrogênio $(\mathrm{N})$ ao ambiente. Estimase que a cada $1 \%$ de redução da $\mathrm{PB}$ em rações para suínos pode-se diminuir a excreção de $\mathrm{N}$ e de amônia em até 8\% (NRC, 2012). Segundo Soumeh et al. (2015), a redução na porcentagem de PB na dieta e o aporte de um perfil mais equilibrado de AA ao animal, que satisfaça as exigências para mantença e crescimento, permite melhorar a utilização do $\mathrm{N}$, reduzindo a sua excreção e contaminação ambiental, sem influenciar o desempenho do animal. Apesar do benefício relacionado ao uso de dietas de baixa $\mathrm{PB}$, quantidades excessivas de leucina em dietas de baixa PB têm reduzido o crescimento, a ingestão de alimento e reduzido à associação de valina e isoleucina (Harper, 1984). Sendo esses efeitos minimizados quando suplementadas quantidades de valina e isoleucina (Gloaguen et al., 2012, Soumeh et al., 2015). Desta forma, as pesquisas relacionadas com AA essenciais, e neste caso os ACR, são de grande importância na nutrição animal, pois eles influenciam diretamente funções fisiológicas de importância produtiva, otimizando a deposição proteica em suínos, melhorando variáveis de produtividade e garantindo um alimento de qualidade para a sociedade.

\section{Metabolismo dos aminoácidos de cadeia ramificada}

As vias de catabolismo dos AA, tomadas em conjunto, normalmente representam apenas 10 a $15 \%$ da produção de energia no organismo humano, sendo menos ativas que a glicose e a oxidação dos ácidos graxos. O fluxo ao longo das vias catabólicas também varia muito, dependendo do equilíbrio entre as necessidades para processos biossintéticos e a disponibilidade de um determinado aminoácido (Lehninger, 2006).

Os AA que estão em excesso, em relação às necessidades para mantença e produção, são catabolizados, sendo o fígado o principal órgão responsável pela sua excreção. No entanto, os ACR que têm estruturas semelhantes são catabolizados principalmente no músculo esquelético e no tecido renal, compartilhando o mesmo sistema de transporte pela membrana celular e utilizando as mesmas enzimas para a degradação e, em parte, as mesmas vias metabólicas (Harper, 1984, Sakomura and Rostagno, 2007). 
Apesar do fígado não catabolizar diretamente os ACR, o mesmo apresenta um sistema muito ativo para a degradação dos cetoácidos de cadeia ramificada, que são os produtos metabólicos dos ACR. A primeira etapa do catabolismo dos ACR é uma transaminação reversível pela isoenzima ATACR (aminotransferase de aminoácidos de cadeia ramificada) e a segunda etapa acontece pelo complexo enzimático desidrogenase de cetoácidos de cadeia ramificada (DCCR), responsável pela descarboxilação oxidativa dos cetoácidos de cadeia ramificada numa reação irreversível (Shimomura and Harris, 2006).

Na primeira fase do catabolismo, a isoenzima ATACR, que é dependente de piridoxal-fosfato, é responsável por aceitar os três ACR como substratos. Em células de mamíferos, duas ATACR estão presentes, sendo uma mitocondrial e outra citosólica. A partir da reação catalisada pela ATACR, os ACR são convertidos nos seus respectivos cetoácidos. A leucina é convertida em $\alpha$-cetoisocaproato (KIC), a isoleucina em $\alpha$-ceto$\beta$-metilvalerato (KMV) e a valina em $\alpha$ cetoisovalerato (KIV) (Rogero and Tirapegui, 2008). Ao mesmo tempo ocorre a transferência de um grupamento amino do aminoácido para o $\alpha$ cetoglutarato, sendo transformado em glutamato, e a partir deste pode ocorrer a síntese de outros AA, como alanina e glutamina. Desse modo, a transaminação dos ACR fornece mecanismos para transferir o $\mathrm{N}$ destes AA de acordo com a necessidade do tecido por glutamato e outros aminoácidos não essenciais (Shimomura and Harris, 2006). Após a ação da ATACR e a formação dos cetoácidos de cadeia ramificada, acontece uma descarboxilação oxidativa mediada pelo complexo enzimático DCCR, presente na superfície da membrana interna da mitocôndria. Por meio da reação catalisada pelo complexo DCCR, os cetoácidos de cadeia ramificada KIC, KMV e KIV são convertidos em isovaleril-CoA, 3-metilbutiril-CoA e isobutiril-CoA, respectivamente. A atividade da DCCR é maior no fígado, intermediária no rim e coração, e comparativamente baixa no músculo estriado esquelético, tecido adiposo e cérebro (Harper, 1984).

A função da enzima DCCR é considerada como a etapa controladora do fluxo do catabolismo dos ACR; ela é altamente regulada por um ciclo de fosforilação/desfosforilação. A enzima DCCR quinase (DCCRQ) promove a inativação da DCCR por meio da fosforilação da subunidade E1 $\alpha$ desse complexo, enquanto a
DCCR fosfatase (DCCRF) é responsável pela ativação do complexo (Figura 2) por meio da desfosforilação da subunidade E1 $\alpha$ (Shimomura et al., 2004).

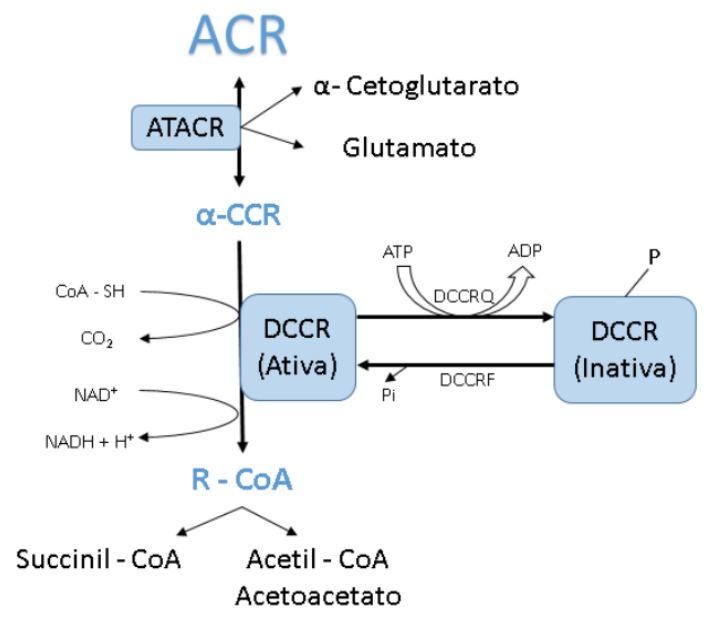

Figura 2. Regulação do complexo enzimático desidrogenase de $\alpha$-cetoácidos de cadeia ramificada (DCCR). (ATACR= aminotransferase de aminoácidos de cadeia ramificada; $\alpha$ $\mathrm{CCR}=\alpha$-cetoácidos de cadeia ramificada; $\mathrm{R}-\mathrm{CoA}=$ acil-CoA) Adaptado de Shimomura et al. (2006).

Finalizada a segunda etapa do catabolismo, os produtos oxidados sofrem outro processo de oxidação por meio de duas diferentes desidrogenases. Assim, as vias catabólicas de cada ACR variam: a leucina é cetogênica e forma acetil-CoA e acetoacetato; a valina é glicogênica, sendo convertida em succinil-CoA; e a isoleucina é cetogênica e glicogênica, pois pode formar acetil-CoA e acetoacetato e succinil-CoA (Figura 3) (Brosnan and Brosnan, 2006).

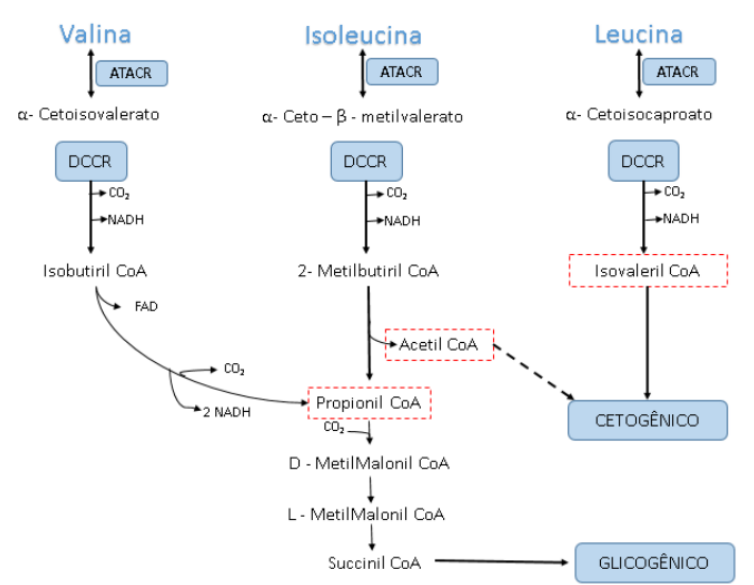

Figura 3. Catabolismo dos aminoácidos de cadeia ramificada (Adaptado de Brody (1998).

Dessa forma, a principal razão para o antagonismo entre os ACR é o aumento da atividade da enzima DCCR, estimulado por altos 
níveis de KIC, que regula de maneira dosedependente a atividade desta enzima, enquanto a valina e isoleucina, bem como seus $\alpha$-cetoácidos, tem pouco ou nenhum efeito na regulação desta enzima (Harper, 1984). Uma vez que os ACR compartilham as primeiras reações do seu metabolismo (Figura 3), um aumento na DCCR, gerado pelo excesso de KIC, reflete-se em maior catabolismo de todos os ACR e, consequentemente, menor disponibilidade destes para a síntese proteica (Murakami et al., 2005). Na fase final do metabolismo dos ACR, os derivados da CoA podem ser destinados para participar no ciclo dos ácidos tricarboxílicos (TCA), por meio da formação do succinil-CoA (Figura 4), ou para a produção de corpos cetônicos, por meio da formação de acetil-CoA e acetoacetato (Lehninger, 2006).

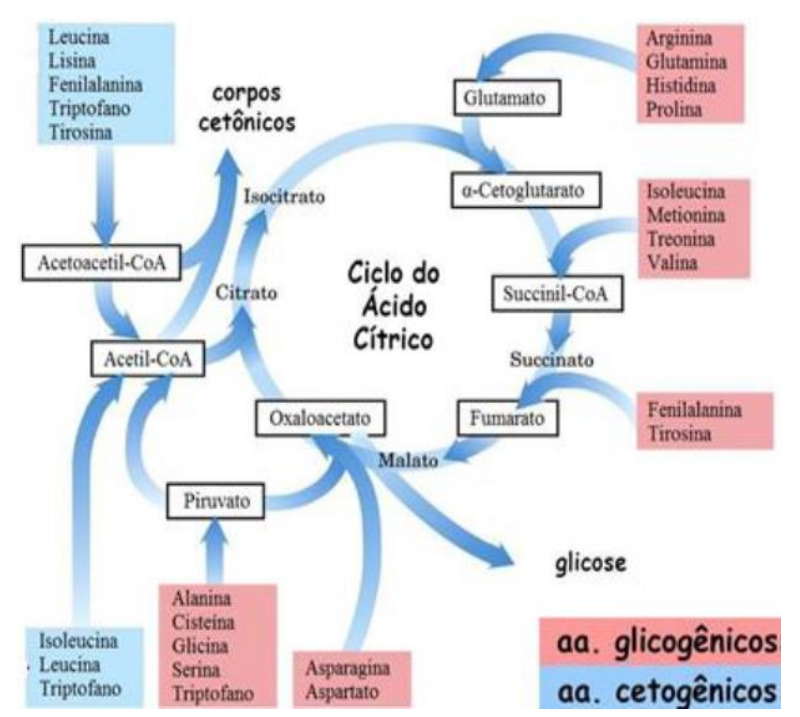

Figura 4. Vias de catabolismo dos aminoácidos (Lehninger, 2006).
As características particulares do catabolismo da valina foram descritas por Shimomura et al. (2004) que relataram que este processo é único quando comparado com os outros ACR. Após a degradação do Isobutiril-CoA é formado o metacrilil-CoA (MC-CoA), um composto tóxico que pode gerar ações mutagênicas e citogênicas, pois é uma molécula reativa com tiol, sendo hidrolisado pela crotonase. Segundo Holden et al. (2001), esta superfamília é também conhecida como enoil-CoA hidratase, possuindo em comum a necessidade de estabilizar um ânion intermediário derivado de um substrato acil-CoA. A crotonase e a $\beta$-Hidroxibutiril-CoA hidrolase (HIB-CoA) são as responsáveis pela rápida eliminação do MC-CoA nas células (Figura 5).

O MC-CoA é gerado durante o catabolismo da valina no espaço da matriz mitocondrial, onde pode reagir com a glutationa e interferir no mecanismo de proteção da mitocôndria contra as espécies reativas de oxigênio (radicais livres). Estudos realizados por Taniguchi et al. (1996) demonstraram uma alta atividade da crotonase e HIB-CoA, mesmo tendo uma atividade constante das DCCR. A alta concentração destas duas enzimas permitiu uma importante proteção fisiológica das células ao hidrolisar a atividade da MC-CoA em ratos. Da mesma forma, Ooiwa et al. (1995) verificaram uma alta atividade das enzimas crotonase e HIB-CoA nos tecidos de cães, sendo a MC-CoA rapidamente degradada. Assim, Shimomura et al. (2004) concluíram que a adição dos ACR, mesmo em alta concentração de valina, não é toxica porque o organismo promove a atividade enzimática da crotonase e HIB-CoA hidratase.

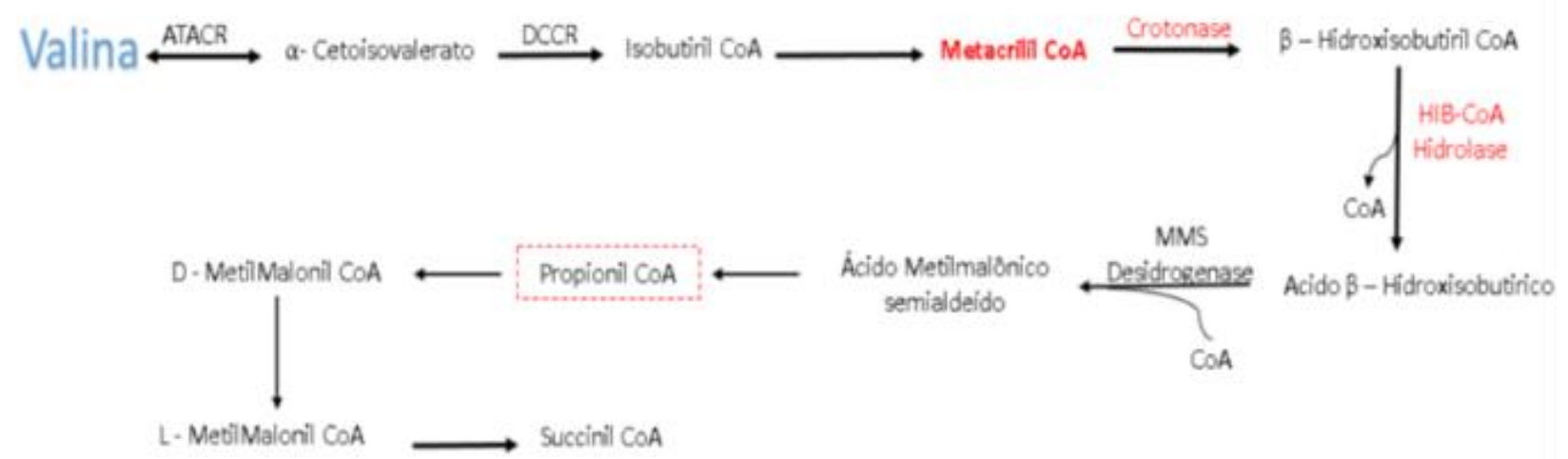

Figura 5. Via catabólica da Valina (Adaptado de Shimomura et al. (2004). 


\section{Antagonismo dos aminoácidos de cadeia ramificada}

Os ACR são estruturalmente semelhantes e compartilham as mesmas vias de degradação no organismo e a sua importância fisiológica tem sido estudada por diferentes pesquisadores, evidenciando uma competição constante pelas vias catabólicas e, como consequência, seu antagonismo (Oestemer et al., 1973, Harper, 1984, Shimomura and Harris, 2006). O antagonismo é uma relação específica entre AA com estrutura similar e, quando existe excesso ou deficiência de um aminoácido, eleva-se a exigência de outro aminoácido, ou seja, devese aumentar ou diminuir a concentração do aminoácido que este em desequilíbrio.

A leucina é o único aminoácido que tem efeitos potentes sobre as duas primeiras etapas do catabolismo dos ACR. A ingestão de uma refeição desequilibrada, contendo grandes quantidades de leucina, geralmente induz a uma redução acentuada na concentração de valina e de isoleucina no organismo. Um equilíbrio positivo de $\mathrm{N}$ é obtido quando a leucina é fornecida na dieta, mas as concentrações dos diversos AA no interior do músculo diminuem, concluindo que há aumento na oxidação dos ACR e aumento da síntese de proteínas, podendo contribuir para o paradoxo da leucina (Shimomura and Harris, 2006).

Estudos realizados por Oestemer et al. (1973) indicaram que os excessos de leucina nas dietas de leitões reduziram consideravelmente os níveis plasmáticos de valina, isoleucina e de seus respectivos $\alpha$-cetoácidos, devido ao aumento da atividade da DCCR, que incrementa a degradação desses dois ACR, ou seja, altos níveis de KIC (produto da degradação da leucina) resultaram em um maior catabolismo dos outros ACR pela estimulação da DCCR. Além de reduzir as concentrações plasmáticas de valina e de isoleucina, o excesso de leucina na dieta provoca outras respostas. Gatnau et al. (1995) avaliaram o efeito do excesso de leucina e seus subprodutos sobre o crescimento e a resposta imunológica de leitões recém desmamados e observaram uma diminuição no ganho de peso diário (GPD) e consumo diário de ração (CDR) quando o nível de leucina foi aumentando na dieta.

A leucina é abundante na maioria dos alimentos, sendo que a exigência dos animais é facilmente atendida, portanto, torna-se difícil criar situações de deficiência severa (Franco, 2011). Assim, os ingredientes normalmente usados nas rações dos suínos podem proporcionar um possível antagonismo com os demais ACR.

O uso de farinha de sangue ou glúten de milho, com $7,7 \%$ e $9,8 \%$ de leucina digestível, respectivamente (Rostagno et al., 2011), em rações para leitões, bem como o uso de dietas com baixo nível de PB, mantendo-se o nível ótimo dos ACR, geram questionamentos sobre um possível antagonismo entre a leucina, isoleucina e valina, uma vez que as concentrações de isoleucina e valina são menores (igura 6).

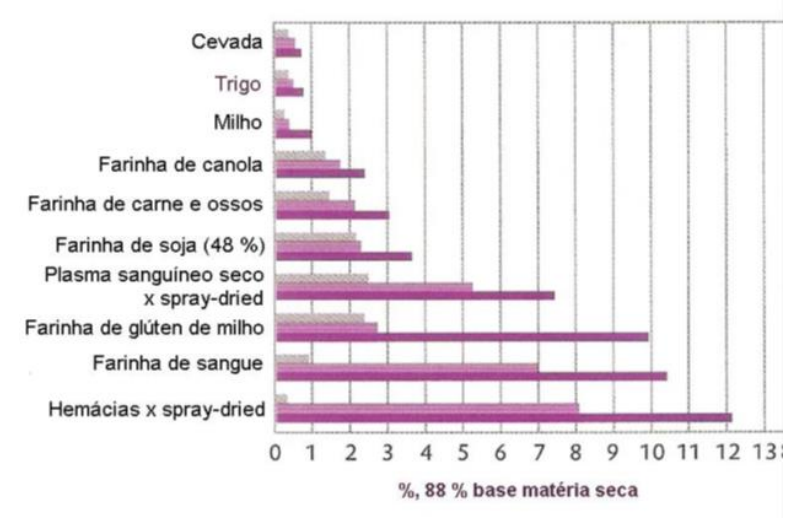

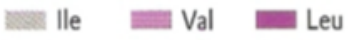

Figura 6. Conteúdo de aminoácidos de cadeia ramificada em ingredientes selecionados (Adaptado de Htoo and Wiltafsky (2012).

Utilizando subproduto do processo de produção do plasma suíno (hemácias secas por pulverização) que possuem uma baixa concentração de isoleucina na sua composição, Kerr et al. (2004) observaram uma redução no CDR, GPD e conversão alimentar (CA) à medida que aumentaram o nível de inclusão de hemácias spray-dried na dieta. No entanto, este subproduto pode ser incluído nas dietas de leitões desmamados até o nível de $6 \%$, sempre que a exigência de isoleucina para esta fase seja atendida. Os mesmos resultados foram encontrados por Van Dijk et al. (2001) trabalhando com leitões desmamados, no entanto a inclusão de até 9,5\% de hemácias spray-dried resultou em diminuição de até $25 \%$ no CDR e uma redução de até $70 \%$ na CA dos leitões. As particularidades de cada fase de crescimento dos suínos podem gerar respostas variadas no consumo, concluindo que a palatabilidade da ração muda quando há inclusão de hemácias secas por pulverização, e como consequência diminui o consumo de ração. 
A suplementação de L-leucina $(0,27$ e $0,55 \%)$ em dietas de baixa PB, $(16,9 \%)$, para leitões com 21 dias de idade, foi objeto do estudo de Yin et al. (2010), os quais observaram que a inclusão de $0,55 \%$ de L-leucina, durante duas semanas, aumentou os níveis de fosforilação da proteína ribossomal S6 quinase 1 (S6K1) e da proteína 1 ligante do fator de iniciação eucariótico 4E (4EBP1), aumentando a síntese proteica no tecido muscular esquelético, fígado, coração, rins, pâncreas, baço e estômago.

Os autores também observaram uma melhora no GPD (61\%) em relação à dieta controle com a inclusão de 0,27\% de L-leucina, sendo que os leitões que receberam esta dieta apresentaram aumento da síntese proteica no intestino delgado, rins e pâncreas. Estes resultados demonstraram que a adição de L-leucina na dieta pode estimular ainda mais a síntese proteica, no entanto, deve-se ressaltar que os níveis de valina e isoleucina não devem estar em excesso, para evitar o antagonismo dos ACR.

Ainda vale ressaltar que os ACR competem com o triptofano pela ligação ao mesmo transportador de AA neutros de cadeia longa (AANCL, valina, isoleucina, leucina, tirosina e fenilalanina) na barreira hemato-encefálica (Henry et al., 1992). Desse modo, a entrada do triptofano no sistema nervoso central (SNC) é regulada pela razão plasmática triptofano livre:ACR e favorecida pela redução da concentração de ACR no sangue, decorrente do aumento da sua taxa de oxidação (Rogero and Tirapegui, 2008), que pode ser relacionada diretamente com a diminuição da produção de serotonina (produto do metabolismo do triptofano) em nível cerebral e, como consequência, apresentar uma redução no consumo de alimento (Feijó et al., 2011).

Em estudo conduzido com suínos machos castrados e fêmeas na fase de terminação foi constatada redução no consumo de ração como consequência da baixa relação entre o triptofano e os AANCL, sendo este efeito relacionado à menor concentração de serotonina, e mais expressivo em fêmeas que em machos castrados (Henry et al., 1992).

Assim, pode-se concluir que o excesso de ACR pode comprometer o consumo de ração, devido à redução da entrada de triptofano no $\mathrm{SNC}$, levando à redução das concentrações de serotonina. Da mesma forma, o excesso de leucina influencia a utilização de valina e isoleucina, devido ao aumento no catabolismo destes AA e o excesso de valina e isoleucina não influenciam de maneira significativa as variáveis de desempenho de suínos, quando comparados com a leucina ( and Wiltafsky, 2012).

\section{Aminoácidos de cadeia ramificada e regulação da síntese proteica muscular}

A síntese proteica no tecido muscular é rapidamente estimulada após a ingestão dos nutrientes na dieta. Alguns benefícios promovidos pela dieta são atribuídos ao alto consumo dos ACR (Vianna et al., 2010), uma vez que estes AA representam 35\% dos AA essenciais presentes na proteína do músculo (Riazi et al., 2003). Pelo fato dos ACR serem metabolizados primeiramente no músculo esquelético, será fonte de energia e substratos para a síntese proteica muscular, sua suplementação poderia influenciar o processo de anabolismo proteico.

É fato que a insulina e AA estimulam o processo de anabolismo, atuando na transcrição genética. Ao administrar uma mistura de AA e glicose pela via endovenosa em ratos, previamente privados de alimentação, Rogero and Tirapegui (2008) observaram um aumento eficiente da síntese proteica no músculo esquelético. Contudo, Manjarrez-Montes-de-Oca et al. (2015) demonstraram, em pesquisas realizadas em animais e humanos, que em condições normais não há efeito anabólico, mas na presença de estresse ou trauma severo (fases de excessiva proteólise) observou-se uma ação contrária ao catabolismo proteico, sugerindo que a leucina e o seu metabólito são ativos nos períodos de estresse excessivo. A leucina exerce os seus efeitos em nível pós-transcricional, no início da fase de tradução do mRNA em proteína (Mata and Navarro, 2009). Assim, o estímulo é dado pelo aumento da concentração deste aminoácido no interior da célula, promovendo a ativação da mTOR ( $\mathrm{Du}$ et al., 2007). Uma das principais funções da mTOR é a síntese proteica no metabolismo celular. A mTOR quinase existe em dois complexos estruturalmente e funcionalmente distintos, o complexo mTOR 1 (mTOR1), sensível à rapamicina; e o complexo mTOR2 (mTOR2) insensível à rapamicina. A mTOR1 é responsável pela regulação da tradução do mRNA, fosforilando a proteína ribossomal S6 quinase 1 (S6K1), o fator de iniciação eucariótico 4G (eIF4G) e a proteína 1 ligante do fator de iniciação eucariótico 4E (4E-BP1). A S6K1 é uma quinase de proteína ribossomal S6 (rpS6) e a sua ativação 
por S6K1 é crucial para a tradução do mRNA (Suryawan et al., 2012, Proud, 2007a). Segundo Hornberger et al. (2006), a mTOR também pode ser ativada pelo crescimento do músculo esquelético, a proteína quinase B (Akt) e fatores de crescimento.

O complexo 4E-BP1 é um inibidor do fator de iniciação da tradução proteica; quando este complexo é fosforilado, se libera o eIF4E unindose ao eIF4G, formando o complexo ativo eIF4G/eIF4E para participar do início da tradução (Rogero and Tirapegui, 2008). A mTOR2 é responsável por regular a ativação da proteína quinase B (Akt) (Proud, 2007b). A montagem desse complexo é necessária para a continuação da etapa de iniciação da tradução do RNAmensageiro em proteína.

A proteína quinase $\mathrm{S} 6$ ribossômica (p70S6k), ativada pela mTOR, é responsável pela estimulação da iniciação dos processos de tradução e de elongação da síntese proteica por diferentes mecanismos. A p70S6k fosforila e inativa a enzima quinase (eEF2K), ativando o fator de elongação eucariótico 2 (eEF2), promovendo a elongação a nível celular (Drummond et al., 2009) e, como resultado, a síntese proteica (Hornberger et al., 2006).

A leucina, juntamente com a insulina, tem um efeito sinérgico e uma influência sobre o controle a curto prazo da etapa de tradução da síntese proteica (Proud, 2007b). A insulina é conhecida como um hormônio anabólico, importante na manutenção da síntese proteica muscular. Atua ainda no transporte de glicose e AA para o interior das células, favorecendo a síntese de proteínas, glicogênio e triglicerídeos (Schneider et al., 2008).

O tecido muscular esquelético é responsável por aproximadamente $75 \%$ da captação de glicose estimulada pela insulina. Este processo se inicia quando a insulina se liga ao seu receptor (IR) na superfície da membrana celular do tecido muscular, estimulando a atividade do IR tirosina quinase. Quando está ativado, o IR fosforila os receptores de insulina (IRS-1 e IRS-2), permitindo que estes substratos se associem e ativem a fosfatidil-inositol 3 quinase (PI3-K), conduzindo à fosforilação da fosfatidil-inositol 2 fosfato (PIP-2) e, como consequência, existe um aumento na concentração de PI3-K no conteúdo celular (Zanchi et al., 2012). Ao mesmo tempo, a Akt é ativada pelo teor de PI3-K, levando ao aumento do transportador de glicose 4 (GLUT4) no citosol; este aumento de GLUT4 faz com que a sua posição seja mudada do citoplasma até a membrana celular, para assim iniciar o processo de captação de glicose pela célula (Wang et al., 1998). Outra via ativada pela Akt, na posição da via de GLUT4, é a via mTOR/p70S6K, o que é importante na síntese de proteínas do músculo esquelético. Esta via é um regulador negativo da sinalização de insulina, levando à fosforilação de resíduos de serina no IRS-1, diminuindo desta forma sua associação com PI3-K (Figura 7) (Zanchi et al., 2012). Segundo Krebs et al. (2002), a leucina estimula a síntese proteica pela modulação de elementos que atuam na tradução da via de sinalização da insulina via fosfatidilinositol 3 quinase (PI3-K), inibindo a sinalização da insulina e diminuindo a utilização de glicose muscular.

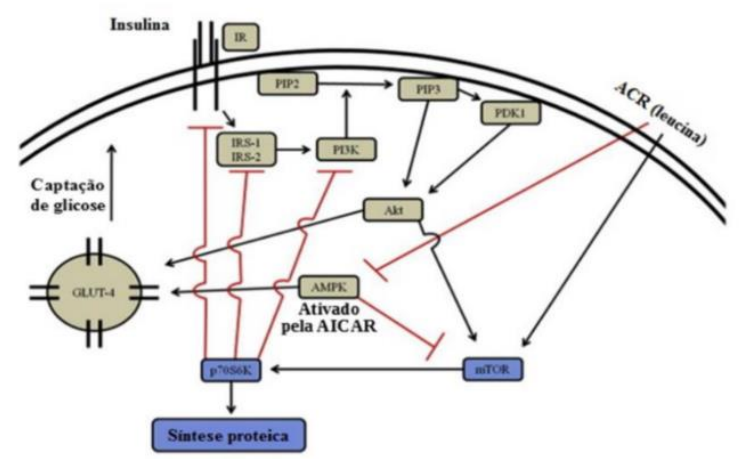

Figura 7. Visão esquemática da leucina no processo de estimulação ou inibição da via de sinalização da insulina no músculo esquelético, conduzido para a síntese de proteína e absorção de glicose (setas pretas) ou resistência à insulina (setas vermelhas) (Adaptado de Zanchi et al. (2012).

Estudos in vitro, realizados por Iwanaka et al. (2010), sobre os efeitos da leucina na estimulação do transporte de insulina nos músculos do antebraço (pronador redondo, flexor radial do carpo, palmar longo e flexor ulnar do carpo) de ratos demonstraram que a leucina tem um efeito estimulador sobre o transporte de glicose, estimulada por contração e um efeito inibitório sobre o transporte da mesma quando há presença de insulina. Da mesma forma, Nishitani et al. (2002) observaram que a administração oral de ACR $(1,5 \mathrm{~g} / \mathrm{kg})$, aumentou a concentração plasmática dos ACR em $2 \mathrm{mM}$ e, após $30 \mathrm{~min}$, houve um aumento no transporte de glicose pela insulina livre no plasma e no músculo de ratos.

Igualmente, Yoon (2016) concluiu que a administração oral de leucina em ratos SpragueDawley aumentou a síntese proteica no tecido adiposo, músculo gastrocnêmio e rim, mas não no fígado e coração, ao contrário das refeições de 
carboidratos, que não alteraram a síntese proteica em nenhum tecido, mas aumentaram a concentração de insulina plasmática. Segundo Macotela et al. (2011), o suplemento dietético de leucina para ratos alimentados com dietas hipercalóricas (gordura) melhora a tolerância à glicose e sensibilidade à insulina, diminuindo problemas como a esteatose hepática e inflamação do tecido adiposo, sem afetar variáveis de desempenho como GPD e CDR.

Por outro lado, Baum et al. (2005), após administrarem leucina oralmente $(1,35 \mathrm{~g} / \mathrm{kg})$ para ratos, não observaram aumento da captação de glicose, nem mudanças na concentração de PI3-K no músculo gastrocnêmio. Resultados similares foram encontrados por Doi et al. (2005), quando administraram via oral uma concentração de 1,35 $\mathrm{g}$ de L-leucina/ $\mathrm{kg}$ de peso em ratos, sem encontrar diferença na concentração de insulina plasmática no músculo gastrocnêmio uma hora após a administração.

\section{Aminoácidos de cadeia ramificada e sua importância na nutrição de suínos}

Conforme relatado anteriormente, os ACR fazem parte dos AA essenciais, os quais são fundamentais para síntese de proteínas e em outros processos fisiológicos do organismo, participando com aproximadamente um terço das proteínas musculares (Gois et al., 2015), sendo a valina o quinto e a isoleucina o sexto aminoácido limitante para suínos. Já a leucina é o ACR que dificilmente estará em deficiência, pois os alimentos convencionais apresentam altos teores deste aminoácido, garantindo altos níveis de leucina em relação à exigência dos suínos.

Os estudos sobre as exigências dos ACR têm sido constantes, pois a importância que eles apresentam nas variáveis zootécnicas faz com que sejam objeto de pesquisa, tanto com relação a seus efeitos no desempenho (CDR, GPD, CA), quanto os efeitos relacionados à fisiologia celular (captação de glicose, síntese proteica, expressão gênica, metabólitos dos ACR, corpos cetogênicos etc).

As pesquisas realizadas por Brinegar et al. (1950) determinaram a exigência de isoleucina (Ile) para leitões recém-desmamados. Os autores incluíram farinha de sangue nas rações experimentais e observaram que o menor nível de Ile $(0,23 \%)$ teve uma resposta negativa para CDR e, como consequência, um menor GPD. Este resultado pode ter sido influenciado pelo problema de palatabilidade que apresenta a farinha de sangue quando usada em altos níveis (Henn et al., 2006). Por outro lado, os níveis de 0,46, 0,58 e $0,70 \%$ de L-isoleucina apresentaram os melhores GPD e CA. Os autores concluíram que o melhor nível de L-isoleucina para esta fase produtiva foi de $0,70 \%$, ao se utilizar dietas com o conteúdo proteico de $22 \%$.

Da mesma forma, Oestemer et al. (1973) avaliaram a relação da leucina (Leu) e Ile na alimentação de leitões recém-desmamados, em que a dieta basal $(0,45 \%$ de Ile e $0,70 \%$ de Leu) foi suplementada com L-Ile e L-Leu para atender os níveis de 0,$45 ; 0,60$ e $0,75 \%$ de Ile, e de 0,70; 0,$78 ; 0,86 ; 0,94$ e $1,02 \%$ de Leu. Os autores não observaram interação Leu x Ile, indicando que a suplementação de Ile foi ineficiente na presença de altos níveis de Leu, sem encontrar uma resposta negativa no GPD dos animais.

Por outro lado, o equilíbrio ótimo entre os ACR (Leucina:Valina:Isoleucina; 1:0,75:0,75 e 0,51:0,63 com 17\% de PB) permitiu aumento no GPD em suínos na fase de crescimento, melhorado o fluxo de ácidos graxos no músculo esquelético, melhorando a qualidade da carne e seu valor nutricional (Duan et al., 2016).

De maneira geral, sempre houve um grande interesse em estudar as exigências dos ACR na nutrição animal, sendo importante ressaltar que esses estudos ajudaram a melhorar a utilização dos AA industriais na dieta. Além disso, com o passar do tempo, diferentes pesquisas mostraram a importância do conceito de proteína ideal e a relação ACR:lisina também foi melhorada.

Pesquisas recentes (Gloaguen et al., 2014, Nørgaard et al., 2015, Soumeh et al., 2015) demonstraram que a concentração da PB das rações está sendo reduzida por meio de formulações baseadas nas exigências dos AA essenciais, como os ACR, lisina e triptofano, bem como utilizando o conceito da PB (Van Milgen and Dourmad, 2015). Reduzindo a porcentagem de PB na dieta de leitões recém-desmamados e avaliando diferentes níveis de valina (Val) em relação à lisina $(0,58 ; 0,62 ; 0,66 ; 0,70 ; 0,74 \mathrm{e}$ $0,78 \%$ ), Soumeh et al. (2015) observaram uma resposta significativa na CA, CDR e GPD, assim como aumento na concentração plasmática de Val. A deficiência de Val influenciou negativamente o CDR e, como consequência, o GPD. Pesquisas realizadas por Gaines et al. (2011) e Gloaguen et al. (2011) mostraram que os níveis ótimos de valina em relação à lisina, para um melhor 
desempenho, são de 63\% para leitões dos 13 aos $32 \mathrm{~kg}$, e de $70 \%$ para leitões dos 10 aos $20 \mathrm{~kg}$, respectivamente. Resultados similares foram encontrados por Gloaguen et al. (2012) ao avaliarem o efeito de uma dieta deficiente em valina e com excesso de leucina para leitões de 4 semanas de idade. Os autores observaram uma depressão no apetite dos leitões após a ingestão da dieta deficiente em valina e, uma hora após o consumo desta dieta, os leitões reduziram o consumo de ração em 14\%, em relação ao grupo controle, além de redução das concentrações de valina e isoleucina no sangue.

A razão leucina:lisina e sua influência na expressão gênica, na concentração plasmática e no desempenho de leitões foi estudada por García et al. (2015), que observaram respostas linear e quadrática para GPD; em contraste, o CDR reduziu linearmente e a CA apresentou uma resposta quadrática. Os autores relacionaram a resposta do GPD com os transportadores catiônicos da lisina e leucina no duodeno, pois a expressão do transportador $b^{0,+}$ (transportador específico da membrana celular intestinal para lisina e leucina) foi maior no jejuno, assim como a alta concentração de lisina no sangue. Os autores concluíram que a relação ideal leucina:lisina é de 100 a $110 \%$, podendo ser utilizada sem influenciar negativamente o desempenho dos suínos. O desequilíbrio dos ACR pode reduzir a utilização da leucina, valina e isoleucina tendo efeito direto nas variáveis de desempenho como consumo de ração e ganho de peso diário e ainda pode influenciar a concentração de alguns parâmetros sanguíneos, como insulina e os corpos cetônicos ( $\beta$-Hidroxi- $\beta$ metilButirato) (Duan et al., 2016).

\section{Conclusão}

A importância dos aminoácidos de cadeia ramificada é a nível nutricional e celular pois influenciam os parâmetros produtivos de eficiência dos suínos assim como o metabolismo proteico. Sendo importante realizar estudos contínuos sobre a relação/interação dos três aminoácidos que constituem este grupo.

\section{Referências Bibliográficas}

Anthony, J. C., Anthony, T. G., Kimball, S. R. \& Jefferson, L. S. 2001. Signaling pathways involved in translational control of protein synthesis in skeletal muscle by leucine. The Journal of Nutrition, 131, 856S-860S.
Baum, J. I., O'Connor, J. C., Seyler, J. E., Anthony, T. G., Freund, G. G. \& Layman, D. K. 2005. Leucine reduces the duration of insulin-induced PI 3-kinase activity in rat skeletal muscle. American Journal of Physiology-Endocrinology and Metabolism, 288, E86-E91.

Brinegar, M. J., Williams, H. H., Ferris, F. H., LOOSE, J. K. \& Maynard, L. A. 1950. The lysine requirement for the growth of swine. Journal of Nutrition, 42, 129-138.

Brody, T. 1998. Nutritional biochemistry. Academic Press.

Brosnan, J. T. \& Brosnan, M. E. 2006. Branchedchain amino acids: enzyme and substrate regulation. The Journal of Nutrition, 136, 207S-211S.

Doi, M., Yamaoka, I., Nakayama, M., Mochizuki, S., Sugahara, K. \& Yoshizawa, F. 2005. Isoleucine, a blood glucose-lowering amino acid, increases glucose uptake in rat skeletal muscle in the absence of increases in AMPactivated protein kinase activity. The Journal of Nutrition, 135, 2103-2108.

Drummond, M. J., Dreyer, H. C., Fry, C. S., Glynn, E. L. \& Rasmussen, B. B. 2009. Nutritional and contractile regulation of human skeletal muscle protein synthesis and mTORC1 signaling. Journal of Applied Physiology, 106, 1374-1384.

Du, M., Shen, Q. W., Zhu, M. J. \& Ford, S. P. 2007. Leucine stimulates mammalian target of rapamycin signaling in $\mathrm{C} 2 \mathrm{C} 12$ myoblasts in part through inhibition of adenosine monophosphate-activated protein kinase. Journal of Animal Science, 85, 919-927.

Duan, Y., Duan, Y., Li, F., Li, Y., Guo, Q., Ji, Y., Tan, B., Li, T. \& Yin, Y. 2016. Effects of supplementation with branched-chain amino acids to low-protein diets on expression of genes related to lipid metabolism in skeletal muscle of growing pigs. Amino Acids, 48, 2131-2144.

Escobar, J., Frank, J. W., Suryawan, A., Nguyen, H. V., Kimball, S. R., Jefferson, L. S. \& Davis, T. A. 2005. Physiological rise in plasma leucine stimulates muscle protein synthesis in neonatal pigs by enhancing translation initiation factor activation. American Journal of Physiology-Endocrinology and Metabolism, 288, E914-E921.

Feijó, F. M., Bertoluci, M. C. \& Reis, C. 2011. Serotonina e controle hipotalâmico da fome: 
uma revisão. Revista da Associação Médica Brasileira, 57, 74-77.

Franco, S. M. 2011. Níveis dietéticos de leucina, de histidina e de fenilalaninat tirosina para frangos de corte na fase inicial. Departamento de Zootecncia. Universidade Federal de Viçosa, Viçosa. Minas Gerais.

Gaines, A. M., Kendall, D. C., Allee, G. L., Usry, J. L. \& Kerr, B. J. 2011. Estimation of the standardized ileal digestible valine-to-lysine ratio in 13-to 32-kilogram pigs. Journal of Animal Science, 89, 736-742.

García, H., Morales, A., Araiza, A., Htoo, J. K. \& Cervantes, M. 2015. Gene expression, serum amino acid levels, and growth performance of pigs fed dietary leucine and lysine at different ratios. Genetics and Molecular Research, 14, 1589-1601.

Gatnau, R., Zimmerman, D. R., Nissen, S. L., Wannemuehler, M. \& Ewan, R. C. 1995. Effects of excess dietary leucine and leucine catabolites on growth and immune responses in weanling pigs. Journal of Animal Science, 73, 159-165.

Gloaguen, M., Floc'h, L., Corrent, E., Primot, Y. \& Van Milgen, J. 2012. Providing a diet deficient in valine but with excess leucine results in a rapid decrease in feed intake and modifies the postprandial plasma amino acid and $\alpha$-keto acid concentrations in pigs. Journal of Animal Science, 90, 3135-3142.

Gloaguen, M., Floc'h, L., Corrent, E., Primot, Y. \& Van Milgen, J. 2014. The use of free amino acids allows formulating very low crude protein diets for piglets. Journal of Animal Science, 92, 637-644.

Gloaguen, M., Le Floc'h, N., Brossard, L., Barea, R., Primot, Y., Corrent, E. \& Van Milgen, J. 2011. Response of piglets to the valine content in diet in combination with the supply of other branched-chain amino acids. Animal, 5, 17341742.

Gois, H. D. S. C., Ferreira, K. C. G., Oliveira, L. C. N. d. \& Bernardo, D. N. D. 2015. Os efeitos da suplementação de ACR sobre a fadiga no exercício de endurance. Revista de Odontologia, 36, 19-22.

Gomez, R. S., Lewis, A. J., Miller, P. S. \& Chen, H. Y. 2002. Growth performance, diet apparent digestibility, and plasma metabolite concentrations of barrows fed corn-soybean meal diets or low-protein, amino acid- supplemented diets at different feeding level. Journal of Animal Science, 80, 644-653.

Harper, A. E. 1984. Interrelationships among the branched chain amino acids. In: S.A., A., Fekl, W., Langenbeck, U. \& Schauder, P. (eds.) Branched chain amino and keto acids in health and disease. Karger Publishers.

Henn, J. D., Ribeiro, A. M. L. \& Kessler, A. d. M. 2006. Comparação do valor nutritivo de farinhas de sangue e de farinhas de vísceras para suínos utilizando-se o método da proteína e gordura digestíveis e o método de substituição. Revista Brasileira de Zootecnia, 35, 1366-1372.

Henry, Y., Seve, B., Colleaux, Y., Ganier, P., Saligaut, C. \& Jego, P. 1992. Interactive effects of dietary levels of tryptophan and protein on voluntary feed intake and growth performance in pigs, in relation to plasma free amino acids and hypothalamic serotonin. Journal of Animal Science, 70, 1873-1887.

Holden, H. M., Benning, M. M., Haller, T. \& Gerlt, J. A. 2001. The crotonase superfamily: divergently related enzymes that catalyze different reactions involving acyl coenzyme a thioesters. Accounts of Chemical Research, 34, 145-157.

Hornberger, T. A., Chu, W. K., Mak, Y. W., Hsiung, J. W., Huang, S. A. \& Chien, S. 2006. The role of phospholipase D and phosphatidic acid in the mechanical activation of mTOR signaling in skeletal muscle. Proceedings of the National Academy of Sciences of the United States of America, 103, 4741-4746.

Htoo, J., M. \& Wiltafsky. 2012. Branched-chain amino acids in broiler nutrition. Aminonews, $16,25-42$.

Iwanaka, N., Egawa, T., Satoubu, N., Karaike, K., Ma, X., Masuda, S. \& Hayashi, T. 2010. Leucine modulates contraction-and insulinstimulated glucose transport and upstream signaling events in rat skeletal muscle. Journal of Applied Physiology, 108, 274-282.

Kerr, B. J., Kidd, M. T., Cuaron, J. A., Bryant, K. L., Parr, T. M., Maxwell, C. V. \& Weaver, E. 2004. Utilization of spray-dried blood cells and crystalline isoleucine in nursery pig diets. Journal of Animal Science, 82, 2397-2404.

Krebs, M., Krssak, M., Bernroider, E., Anderwald, C., Brehm, A., Meyerspeer, M., Nowotny, P., Roth, E., Waldhäusl, W. \& Roden, M. 2002. Mechanism of amino acid-induced skeletal 
muscle insulin resistance in humans. Diabetes, 51, 599-605.

Lehninger, N. D. L. 2006. Principios de bioquímica. São Paulo.

Lordelo, M. M., Gaspar, A. M., Le Bellego, L. \& Freire, J. P. B. 2008. Isoleucine and valine supplementation of a low-protein corn-wheatsoybean meal-based diet for piglets: growth performance and nitrogen balance. Journal of Animal Science, 86, 2936-2941.

Macotela, Y., Emanuelli, B., Bång, A. M., Espinoza, D. O., Boucher, J., Beebe, K., Gall, W. \& Kahn, C. R. 2011. Dietary leucine-an environmental modifier of insulin resistance acting on multiple levels of metabolism. PloS One, 6, e21187.

Manjarrez-Montes-de-Oca, R., Torres-Vaca, M., González-Gallego, J. \& Alvear-Ordenes, I. 2015. El B-hidroxi-B-metilbutirato (HMB) como suplemento nutricional (I): metabolismo y toxicidad. Nutricion Hospitalaria, 31, 590596.

Mata, G. R. \& Navarro, F. 2009. O efeito da suplementação de leucina na síntese protéica muscular. Revista Brasileira de Nutrição Esportiva, 3, 367-378.

Murakami, T., Matsuo, M., Shimizu, A. \& SHIMOMURA, Y. 2005. Dissociation of branched-chain $\alpha$-keto acid dehydrogenase kinase (BDK) from branched-chain $\alpha$-keto acid dehydrogenase complex (BCKDC) by BDK inhibitors. Journal of Nutritional Science and Vitaminology, 51, 48-50.

Nishitani, S., Matsumura, T., Fujitani, S., Sonaka, I., Miura, Y. \& Yagasaki, K. 2002. Leucine promotes glucose uptake in skeletal muscles of rats. Biochemical and Biophysical Research Communications, 299, 693-696.

Nørgaard, J. V., Pedersen, T. F., Soumeh, E. A., Blaabjerg, K., Canibe, N., Jensen, B. B. \& Poulsen, H. D. 2015. Optimum standardized ileal digestible tryptophan to lysine ratio for pigs weighing 7-14kg. Livestock Science, 175, 90-95.

NRC. 2012. Nutrient Requirements of Swine, 7th rev. edn. Natl. Acad. Press, Washington, DC., Washington.

Oestemer, G. A., Hanson, L. E. \& Mendes, R. 1973. Leucine-isoleucine interrelationship in the young pig. Journal of Animal Science, 36, 674-678.
Proud, C. G. 2007a. Amino acids and mTOR signalling in anabolic function. Biochemical Society Transactions, 35, 1187-1190.

Proud, C. G. 2007b. Signalling to translation: how signal transduction pathways control the protein synthetic machinery. Biochemical Journal, 403, 217-234.

Riazi, R., Wykes, L. J., Ball, R. O. \& Pencharz, P. B. 2003. The total branched-chain amino acid requirement in young healthy adult men determined by indicator amino acid oxidation by use of L-[1-13C] phenylalanine. The Journal of Nutrition, 133, 1383-1389.

Richardson, L. R., Hale, F. \& Ritchey, S. J. 1965. Effect of fasting and level of dietary protein on free amino acids in pig plasma. Journal of Animal Science, 24, 368-372.

Rogero, M. M. \& Tirapegui, J. 2008. Aspectos atuais sobre aminoácidos de cadeia ramificada e exercício físico. Revista Brasileira de Ciências Farmacêuticas, 44, 563-575.

Rostagno, H. S., Albino, L. F. T., Donzele, J. L., Gomes, P. C., Oliveira, R., Lopes, D. C., Ferreira, A. S., Barreto, S. \& Euclides, R. F. 2011. Composição de alimentos e exigências nutricionais, 3 edn. Universidade Federal de Viçosa, Viçosa.

Sakomura, N. K. \& Rostagno, H. S. 2007. Métodos de pesquisa em nutrição de monogástricos. FUNEP, Jaboticabal.

Schneider, A., Schwegler, E., Goulart, M. A., Roos, T. B., Rabassa, V. R., Del Pino, F. A. B., Pfeifer, L. F. M. \& Corrêa, M. N. 2008. Efeito do jejum e da administração de insulina sobre os parâmetros metabólicos de ovelhas em confinamento. Acta Scientiae Veterinariae, 36, $39-42$.

Shimomura, Y. \& Harris, R. A. 2006. Metabolism and physiological function of branched-chain amino acids: discussion of session The Journal of Nutrition, 136, 232S-233S.

Shimomura, Y., Honda, T., Shiraki, M., Murakami, T., Sato, J., Kobayashi, H., Mawatari, K., Obayashi, M. \& Harris, R. A. 2006. Branched-chain amino acid catabolism in exercise and liver disease. The Journal of Nutrition, 136, 250S-253S.

Shimomura, Y., Murakami, T., Nakai, N., Nagasaki, M. \& Harris, R. A. 2004. Exercise promotes BCAA catabolism: effects of BCAA supplementation on skeletal muscle during 
exercise. The Journal of Nutrition, 134, 1583S$1587 \mathrm{~S}$.

Soumeh, E. A., Van Milgen, J., Sloth, N. M., Corrent, E., Poulsen, H. D. \& Nørgaard, J. V. 2015. Requirement of standardized ileal digestible valine to lysine ratio for 8 -to $14-\mathrm{kg}$ pigs. Animal, 9, 1312-1318.

Suryawan, A., Nguyen, H. V., Almonaci, R. D. \& Davis, T. A. 2012. Differential regulation of protein synthesis in skeletal muscle and liver of neonatal pigs by leucine through an mTORC1dependent pathway. Journal of Animal Science and Biotechnology, 3, 1-10.

Taniguchi, K., Nonami, T., Nakao, A., Harada, A., Kurokawa, T., Sugiyama, S., Fujitsuka, N., Shimomura, Y., Hutson, S. M. \& Harris, R. A. 1996. The valine catabolic pathway in human liver: effect of cirrhosis on enzyme activities. Hepatology, 24, 1395-1398.

Van Dijk, A. J., Everts, H., Nabuurs, M. J. A., Margry, R. J. C. F. \& Beynen, A. C. 2001. Growth performance of weanling pigs fed spray-dried animal plasma: a review. Livestock Production Science, 68, 263-274.

Van Milgen, J. \& Dourmad, J.-Y. 2015. Concept and application of ideal protein for pigs. Journal of Animal Science and Biotechnology, 6, 6-15.

Vianna, D., Teodoro, G. F. R., Torres-Leal, F. L. \& Tirapegui, J. 2010. Protein synthesis regulation by leucine. Brazilian Journal of Pharmaceutical Sciences, 46, 29-36.

Wang, X., Campbell, L. E., Miller, C. M. \& Proud, C. 1998. Amino acid availability regulates p70
S6 kinase and multiple translation factors. Biochemical Journal, 335, 711-711.

$\mathrm{Wu}, \quad$ G. 2014. Dietary requirements of synthesizable amino acids by animals: a paradigm shift in protein nutrition. Journal of Animal Science and Biotechnology, 5, 34.

Yin, Y., Yao, K., Liu, Z., Gong, M., Ruan, Z., Deng, D., Tan, B., Liu, Z. \& Wu, G. 2010. Supplementing L-leucine to a low-protein diet increases tissue protein synthesis in weanling pigs. Amino Acids, 39, 1477-1486.

Yoon, M.-S. 2016. The emerging role of branched-chain amino acids in insulin resistance and metabolism. Nutrients, 8, 1-13.

Zanchi, N. E., Guimarães-Ferreira, L., SiqueiraFilho, M. A., Camporez, J. P. G., Nicastro, H., Chaves, D. F. S., Campos-Ferraz, P., Lancha, A. H. \& Oliveira Carvalho, C. R. 2012. The possible role of leucine in modulating glucose homeostasis under distinct catabolic conditions. Medical Hypotheses, 79, 883-888.

Zangeronimo, M. G., Fialho, E. T., Lima, J. A. F., Rodrigues, P. B. \& Murgas, L. D. S. 2006. Redução do nível de proteína bruta da ração suplementada com aminoácidos sintéticos para leitões na fase inicial. Revista Brasileira de Zootecnia, 35, 849-856.

Article History:

Received 11 July 2017

Accepted 2 August 2017

Available on line 30 August 2017

License information: This is an open-access article distributed under the terms of the Creative Commons Attribution License 4.0, which permits unrestricted use, distribution, and reproduction in any medium, provided the original work is properly cited. 